\title{
Conflict Resolution Through Training on Emotional Intelligence and Empathy in a Workplace-
}

\author{
An Empirical Study \\ Umashankar K (Corresponding author) \\ Faculty- Dept. of Behavioural Science, Manipal University Bangalore Campus \\ E-mail: shankartagore@gmail.com
}

Charitra HG

Asst. Professor, Krupanidhi College, Bangalore

Received: May 29, 2014 Accepted: June 24, 2014 Published: June xx, 2014

doi:10.5296/rbm.v1i2.5865 URL: http://dx.doi.org/10.5296/rbm.v1i2.5865

\begin{abstract}
The contemporary workplaces have been encountering with substantial number of conflicts among the colleagues resulting in fading relationships and loss of work productivity. Besides, the subtle conflicts characterized by lack of empathy or selfish motive among the colleagues result in low commitment towards the work. In this regard, the corporate sectors have identified training programs on Emotional Intelligence and empathy training as an intervention.

In this paper, the researcher incorporates Emotional intelligence and Conflict Management Styles as the important variables in studying the conflicting nature of the subjects that were under observation. The researcher hypothesizes that an intervention program on emotional intelligence and empathy may reduce the frequency of conflicts among the subjects.

Further, the researcher designed the intervention program for the experiment group and the control group was kept under observation. As hypothesized, the experiment group showed a remarkable progress after the intervention program compared to the control group. Besides, the assessment tools for Emotional Intelligence and Conflict management styles were incorporated in this research.
\end{abstract}

Keywords: emotional intelligence, conflict management styles, social mapping, empathy training 


\section{Introduction}

During a few decades, a set of conventional life skills and expertise in the knowledge domain was sufficient to carry out day to day endeavours in the workplace. However, the contemporary world has trailed through drastic metamorphosing edges of the world market. Wherein, the demands of the consumer market have been constantly and consistently changing every day and the companies have to update their marketing strategies and empower their human resource according to the changing demands.

Moreover, the manpower was being constantly upgraded on the lines of soft-skills and domain expertise based on the prevailing trends. The periodic soft-skills training was being provided for the manpower based on communication, stress management, etc... However, the experts of human resource considered that the Intelligence Quotient was being a predominant one in order to excel in one's professional career.

In 1983, Howard Gardner had challenged the idea and proposed the multiple intelligence theory that consists of seven categories in order to accurately define the concepts of intelligence and to succeed in the field. Two of them are intrapersonal intelligence, the ability to understand oneself and act on the basis of self-knowledge, and interpersonal intelligence, the ability to work cooperatively and communicate with other people effectively (Helfrich, 2009). In the contemporary world, they are now often referred to in association with emotional intelligence, ability to understand, perceive and regulate the feelings, emotions and motivation of one's self and of others (Goleman, 1998).

Emotional intelligence (EI) involves the capacity to perceive emotions, assimilate emotion-related feelings, understand the information of emotions, and manage emotions (Mayer, Salovey \& Caruso, 2000). The findings of various studies indicated that EI could have an impact on several organizational and individual domains. Further, Emotional intelligence is considered to be a motivating force for one's professional development (Van Rooy \& Viswesvaran, 2004), contributing to the actualization if organizational goals and vision (Barling, Slater \& Kelloway, 2000; Gardner \& Stough, 2002; Shipper, Kincaid, Rotondo \& Hoffman, 2003). As a result of new findings pertaining to the work relationships in connection to emotional intelligence, the departments of Human Resources are increasingly incorporating intervention programs on Emotional Intelligence and amiable conflict management styles.

The rationale for the introduction of these programs is under the belief that the employees can increase their awareness of regulating their emotions during the interpersonal interactions and finally it will lead them to healthy relationships at workplace (Schutte et al., 2001; Wong, Foo, Wang \& Wong, 2007), further, contributing to the overall development of the organization. For example, some recent research evidence has shown that EI development and training has resulted in reduced occupational stress and improved health, well-being and management performance (Gardner, 2005; Hansen, Gardner \& Stough, 2007; Slaski \& Cartwright, 2003).

\section{Conflict and the Conflict Management:}

Conflict is a situation wherein prevails a friction between two or more individuals (Ego 
clashes or differences in opinion or intentions) leading to barren results or leading to some of the solutions that helps in problem resolution/innovation. In the light of the given statement on conflict, it can be ascertained that the conflict may be productive or unproductive (conflicts are unproductive most of the times). However, the conflicts are pan existent in nature and prevail in most of the human conditions. The conflicts being unproductive most of the times hamper the work efficiency of the individual or teams finally leading to low productivity. Therefore, the conflict management strategies have to be incorporated according to the situations in order to ensure the high efficacy of teams and the organizational goals may be achieved through these empowered teams. According to the previous research, there is a significant relationship between emotional intelligence and subordinates' styles (e.g., Yu, Sardessai, Lu \& Zhao, 2006). According to this research, the people with high emotional intelligence adopt collaborative style of conflict management (both parties find a creative solution to satisfy both parities' concerns) and the compromising style (both parties win some and lose some, in an attempt to reach a consensus) of conflict management.

\section{Purpose of the Study}

The purpose of this study is to provide the organization with an insight about the relationship between emotional intelligence and managing conflicts among the colleagues. These findings give the organization the necessary information to motivate their employees in increasing their work performance; if it is shown that a lack of emotional intelligence hinders the communication between them. Moreover, it has also been found that lack of emotional intelligence may result in frequent conflict among the work group. Hence the researcher felt the need for understanding the role of emotional intelligence in neutralizing unproductive conflicts among the employees. Accordingly, the researcher may possibly suggest some intervention programs to increase the EQ level among the employees. Further, it is also inferred that the conflicts among the employees are left undiagnosed and untreated, it will obviously result in downward shift in one's work performance affecting the entire organizational setup.

With reference to this study, the researcher intents to establish the relationship between emotional intelligence and cordial workplace interpersonal relationships. Besides, it is also inferred that the importance of emotional intelligence could be ascertained during the adoption of relevant conflict management styles.

Furthermore, in this explorative study, an EI intervention (i.e. training program) was implemented with the aim of establishing whether this training program was instrumental in combating various negative facets of the occupational stress process, experienced by the professionals. It was hypothesized that following participation in the EI training program, the participants' levels of EI will increase, and that their levels of perceived occupational stress will decrease. Furthermore, it was hypothesized that levels of psychological- and physical health will improve following participation in the training program, as well as the outcomes of stress 


\section{Macrothink \\ Research in Business and Management \\ ISSN 2330-8362 \\ 2014, Vol. 1, No. 2}

\section{Introduction to the Organization}

Zest Education Services Pvt. Ltd (the name changed) is an esteemed academic portal that focuses at training the various levels of students in India. Besides, the organization also provides training to the various academic establishments on consultancy basis. In addition, there are approximately two hundred faculty members in the organization.

\section{Definition of Terms}

\subsection{Emotional Intelligence}

Emotional intelligence can be referred to as knowing and using one's feeling in appropriate manner, motivating oneself and others effectively, and managing the relationships by exhibiting empathy and interacting smoothly to one another (Goleman, 1998). According to Goleman (1998), the five components of emotional intelligence are self-awareness, self-regulation, social skills, motivation and empathy.

5.1.1 Self-awareness (SA) refers to one's ability to understand the internal state of emotional well-being, inclinations, preferences and the interplay of positive and destructive emotions.

5.1.2 Self-regulation (SR) means how an individual can regulate the internal conditions and manage the flow of emotions.

5.1.3 Motivation (MO) refers to the factors that drive an individual to achieve their goals

5.1.4 Empathy (EM) refers the individual's skill to understand other emotional status or psychological status of other through interpersonal communication.

5.1.5 Social skills (SS) are referred to infusion of an individual's preferences into others without offending their ego or propensity.

\subsection{Conflict Management Styles}

Conflict Management Styles refer to a handling strategy of an individual during a conflicting situation. In this regard, the person involved in a situation decides the right approach to handle the situation. According to Thomas Kilmann, there are five types of conflict management styles:

5.2.1 Competing is an uncooperative and aggressive approach wherein the individual tries to put across his own ambitions or opinions across the situation having no regard for others.

5.2.2 Accommodating approach involves amicable and cooperative move of an individual wherein the person has consideration for every individual in the group and ensures that the every one works for achieving the common goal.

5.2.3 Avoiding is unassertive and uncooperative wherein the individual tries to go away from the situation without involving.

5.2.4 Collaborating is both assertive and cooperative - the complete opposite of avoiding.

5.2.5 Compromising involves moderate assertiveness and cooperativeness wherein the 
individual sacrifices his/her own interests while considering other opinions.

\section{Limitations of the Study}

Following are the limitations of the study;

- As the study focused mainly on the conflicts among the subjects with reference to their emotional intelligence, the study may not include the other factors like gender, socio-economic background or their personal backgrounds.

- The subjects might not be too frank in filling up the questionnaire and that might lead to misinterpretation of data acquired.

- The observation period of month (including weekly offs) might not be sufficient to map the conflicts among the individuals.

\section{Methodology:}

This study's purpose was to investigate the relationship between emotional intelligence and conflict management styles among the trainers in Zest Education Services Pvt. Ltd (name changed), Bangalore. From this study, the researcher hoped to identify both the relationship of the two variables, and how this study would be able to provide recommendations from the findings to improve the performance of the organization. This section will outline multiple aspects of the research conducted, including: research objectives, planning, instrumentation utilized, participant/subjects, data collection and analysis procedures, and limitations of the study. The following research objectives and expectations were established by the researcher and agreed upon by all parties involved (Figure 1).

\section{Planning}

The researcher aimed at studying the conflicting behaviour of the subjects with reference to the emotional intelligence. Further, he selected thirty candidates from the organization and listed their names for social mapping among them over the period of one month (Nov. 1 to Nov. 30) and the conflicts were recorded on daily basis. Prior to the social mapping, the researcher selected the psychological instruments for measuring the Emotional intelligence and the conflict management styles among the subjects.

\section{Subject Selection and Description}

The subjects were selected from the specific department of the organization wherein the subjects are working as the trainers. Pertaining to their academic background, all the trainers are post-graduates (some have PhDs) and they are working together. During the period of study, all the identified subjects were available for personal observation. Based on the observation of the researcher over a period of 5 years pertaining to the prevailing conflicts, he decided to do a study on the emotional intelligence of a person and its impact on their conflicting behaviour. 


\section{Instrumentation}

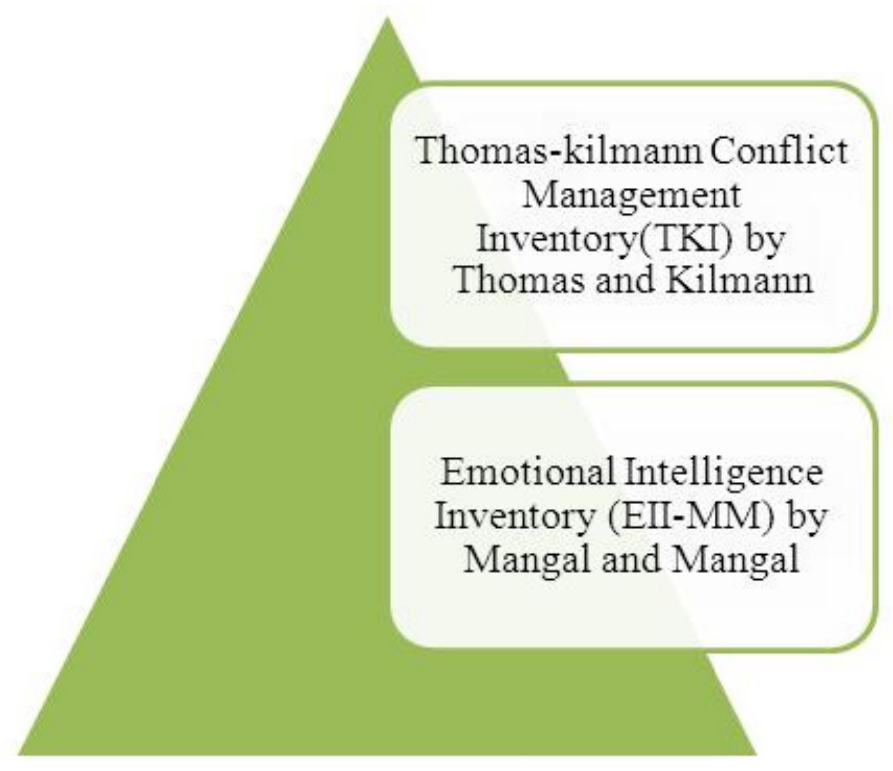

Figure 1. Instruments for the present study

The study included Thomas-Kilmann Conflict Management Inventory by Thomas and Kilmann and Emotional Intelligence Inventory (EII-MM) by Mangal and Mangal for measuring conflict management styles and emotional intelligence respectively.

10.1 Emotional Intelligence Inventory (EII-MM) by Mangal and Mangal: the following figure describes the test in brief:

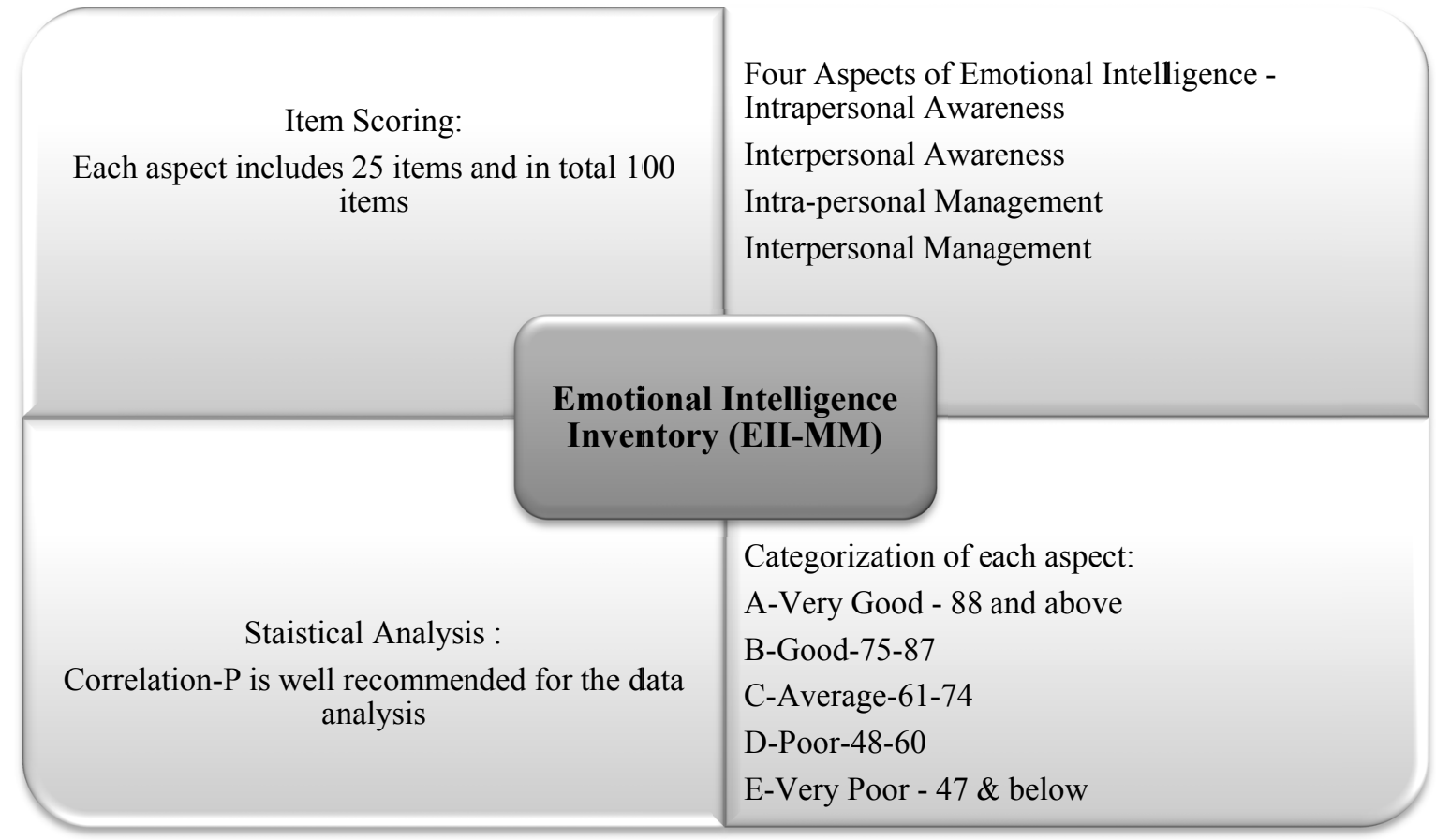

Figure 2. Description of Emotional Intelligence Inventory (EII-MM) 
10.2 Thomas-Kilmann Conflict Management Inventory by Thomas and Kilmann

The Thomas-Kilmann Inventory (TKI) is a self-reporting instrument which examines behaviour and determines whether individuals are over- or under-using one or more of five conflict-handling modes: competing, collaborating, compromising, avoiding and accommodating. These five approaches are mapped across two basic dimensions assertiveness (from unassertive to assertive) and cooperativeness (uncooperative to cooperative).

\section{Data Collection}

As a part of the data collection, the instruments on emotional intelligence and conflict management styles were administered on the selected subjects who were thirty in number. Later, social mapping was undertaken by the researcher over the period of one month. Accordingly, the researcher divided the 30 subjects into two groups that is Experiment Group (15 members) and Control Group (15 members). The control group included the members who had higher frequency of conflicts compared to experiment group. The researcher had due ethical considerations while administering the tests wherein it was ensured to the subjects that the results would be kept confidential.

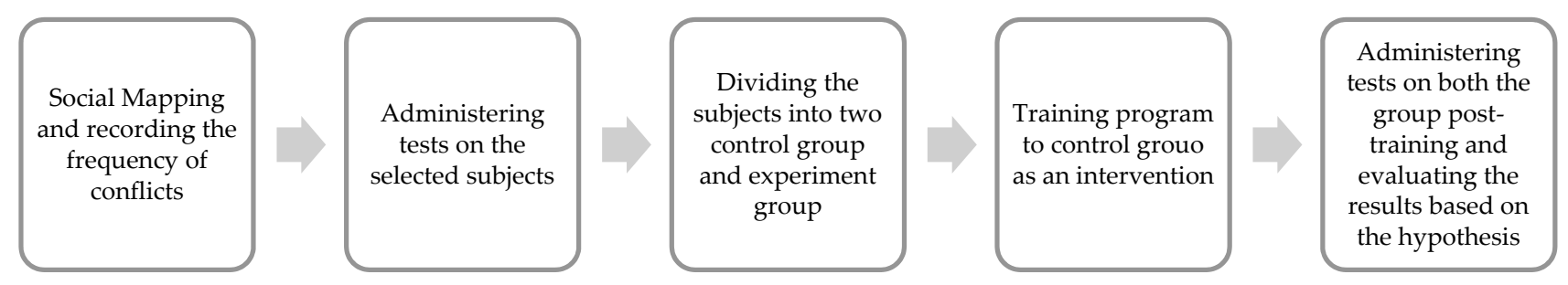

Figure 3. Stages of Data Collection

\section{Procedure for Data Collection}

The two psychological tests were identified for the data collection. In addition, the researcher carried out the social mapping was not disclosed to the subjects. The questionnaire on emotional intelligence through paper-pencil test and the questionnaire on conflict management were administered through e-mails. Later, the data was recorded on the excel sheet and the intervention program was carried out. Later, the post-administration of the questionnaires were carried out through emails. 


\section{Data Interpretation:}

\subsection{Social Mapping in the Month of November}

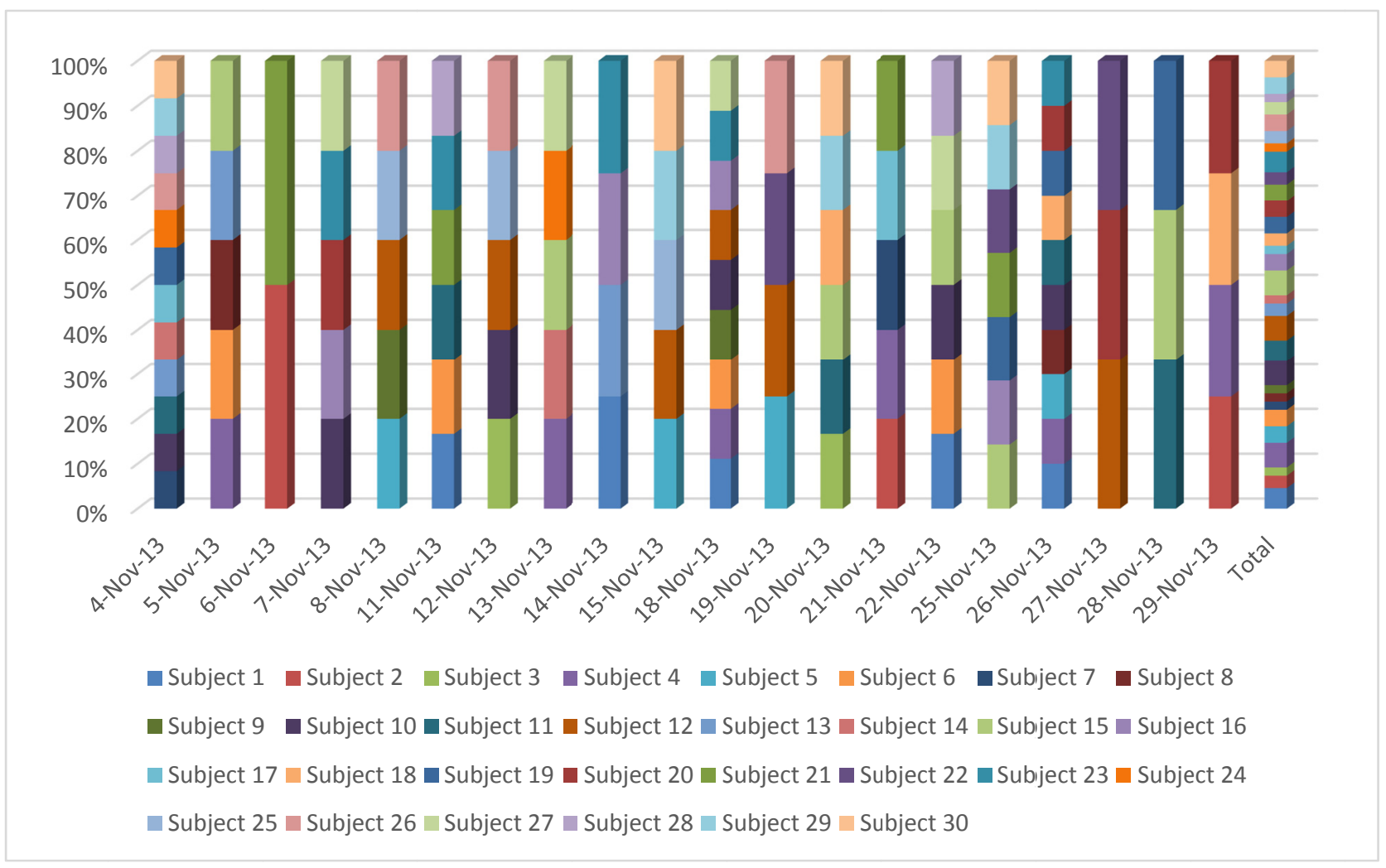

Figure 1. Social Mapping November 2013

As per the objectives of the study, the researcher planned for social mapping in order to record the number of incidents of conflicts among the subjects and the subjects were thirty in number. As it is reflected in the graph 7, each subject is represented by a color reflecting their involvement in the conflict on day to day basis. Further, the above graph also reflects the frequency of conflicts that each member had on day to day basis for one month and the frequency of conflicts that each individual had in total over a period of one month. 


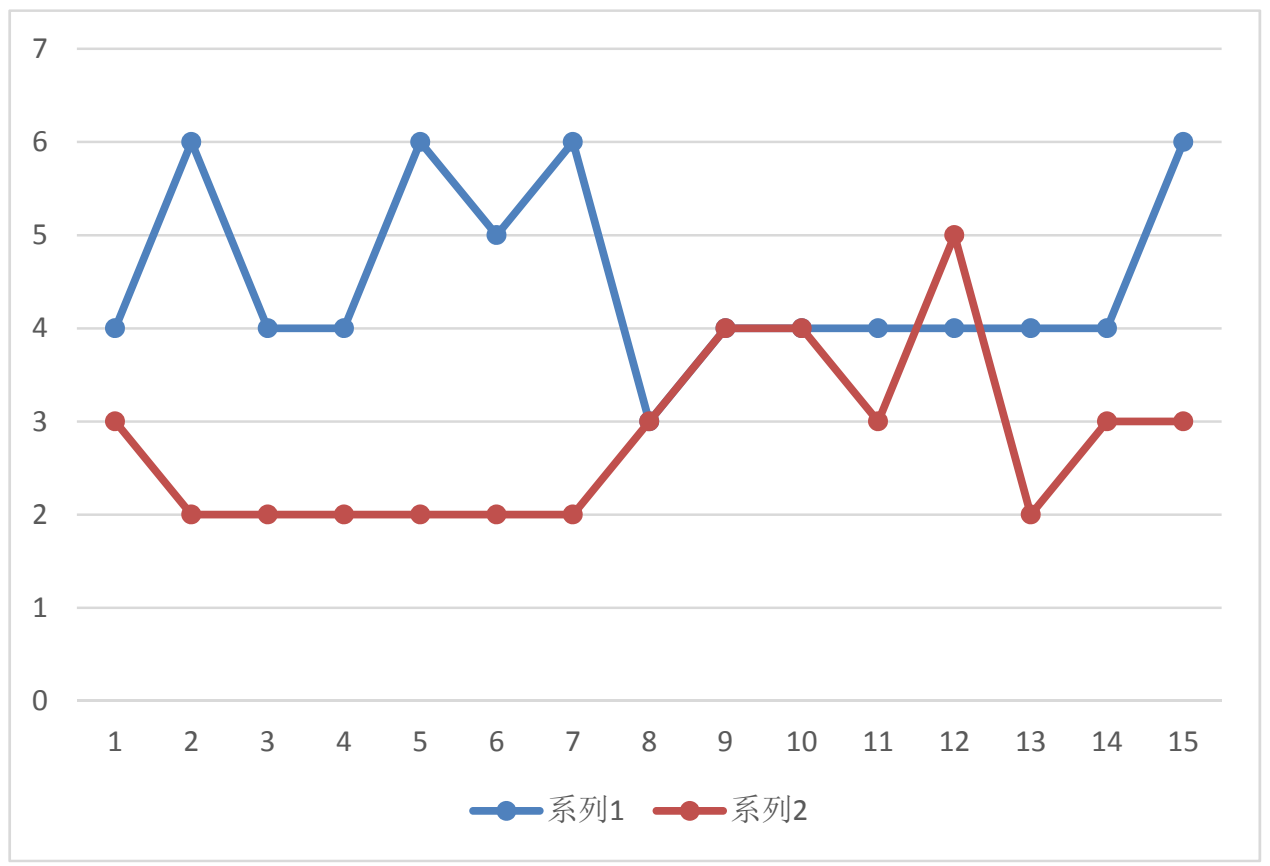

Figure 2. Graphical Analysis of Experiment Group (Series1) \& Control Group (Series2)

The later stage of social mapping included the division of thirty subjects into two groups that is Experiment group and Control Group based on the frequency of conflicts that they had during the period of one month. As reflected in the graph, the Experiment Group (Mean: 4.53) had increasingly more frequency of conflicts compared to the control group (Mean: 2.8, Correlation: 0.413). The diagonal series of numbers (Y Axis) reflect on the maximum frequency of conflicts an individual had during the period and the parallel series of numbers (X Axis) reflect on the number of subjects. 


\section{Macrothink}

13.2 Administration of Tests (Emotional Intelligence Inventory \& Conflict Management Inventory): During the month of November, the researcher administered the tests on 30 subjects.

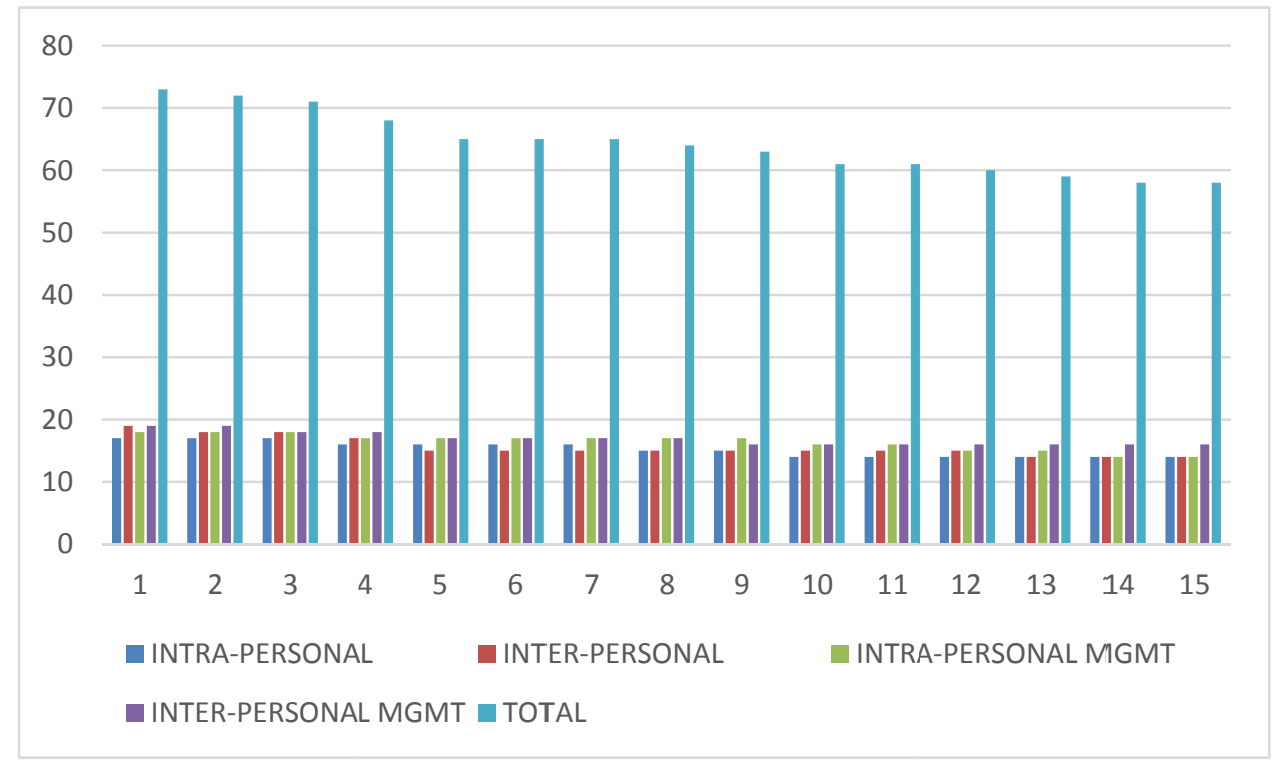

Figure 3. Experiment Group EI Scores - Pre Training

The above graph reflects on the scores obtained by each subject on various parameters like: intrapersonal awareness, interpersonal awareness, intrapersonal management and interpersonal management. The $\mathrm{Y}$ axis reflects on the maximum score attained by each individual out of 100 and the scores obtained in each parameter out of 25.

\subsection{Pre-training EI score analysis of experiment and control group:}

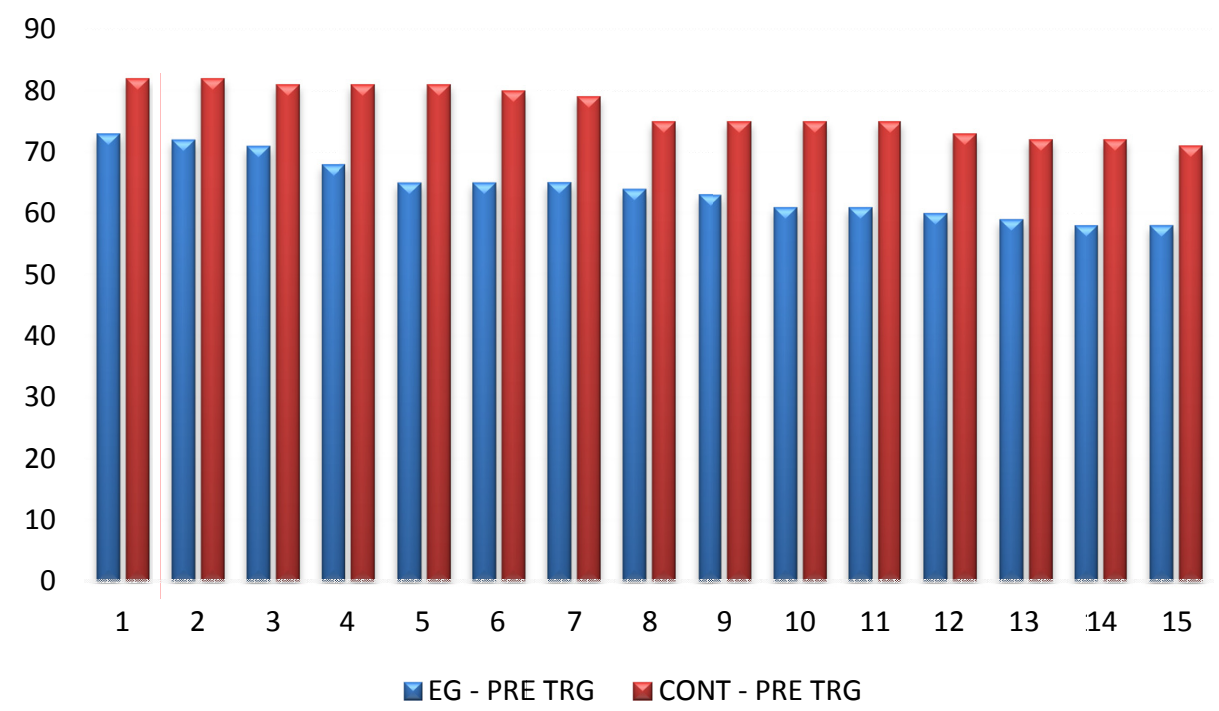

Figure 4. Pre training Analysis of Control group and experiment group - EI scores 


\section{Macrothink}

The EI test was administered on both the experiment group and the control group and recorded their status of emotional intelligence. As reflected in the graph, the blue color indicates the experiment group and red stripe indicates the control group. As per the survey, it has been observed that the members who were under the experiment group had scored less compared to the control group. Accordingly, it could be declared that the members in the experiment group had less emotional intelligence compared to the other group. The average score of the members of Experiment group is 64.2 and the average score of control group is 76.93. In continuation, the Standard Deviation is 0.92 which is comparatively high.

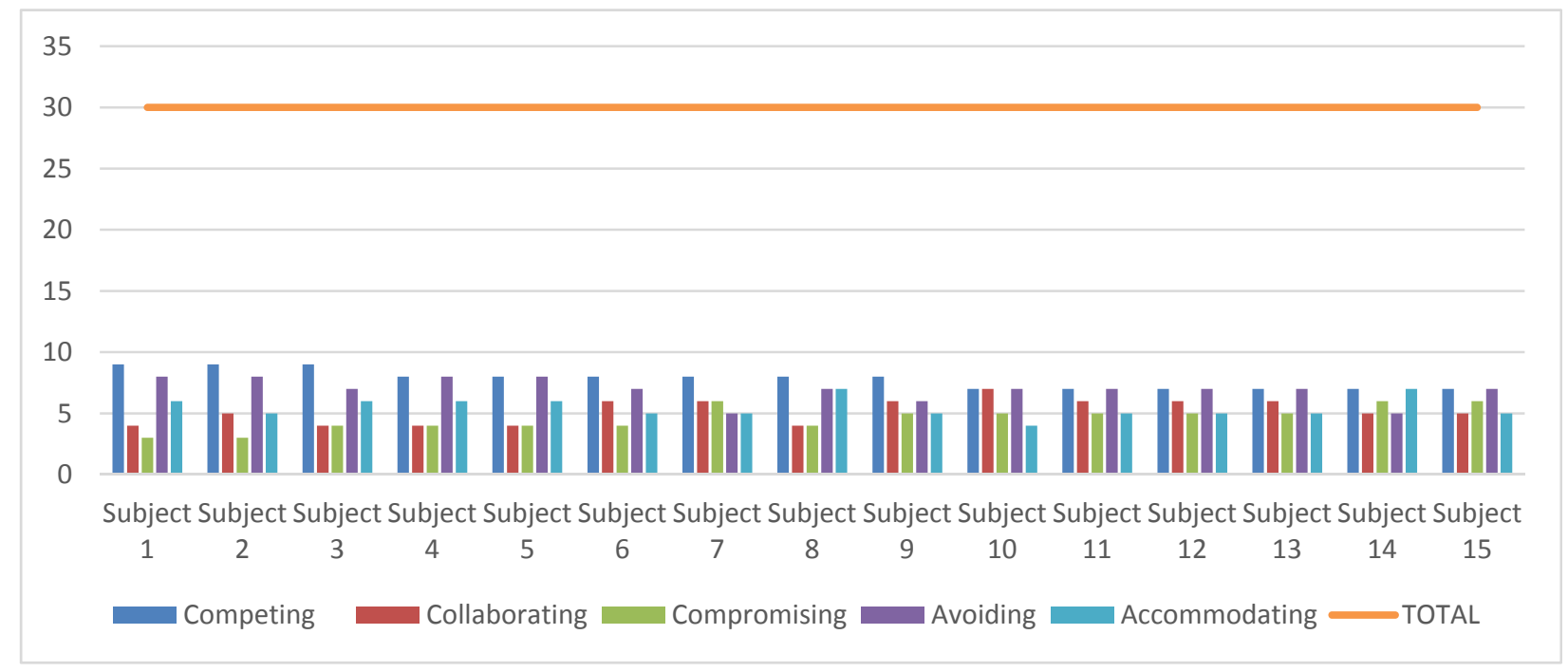

Figure 5. Pre-trg Experiment Group - Conflict Management Scores

In addition to the administration of Emotional Intelligence Inventory, the researcher simultaneously administered the Thomas-Kilmann's Conflict Management Inventory in order to assess the influence of an individual's EI on his/her conflict management styles on both experiment and control groups.

The above graph reveals that the conflict management styles of fifteen subjects who were in the experiment group. The inventory included five conflict management styles; Competing (Mean: 7.35 - SD: 0.74), Collaborating (Mean-4.93 - SD: 0.97), Compromising (Mean-4.37, SD-0.95), Avoiding (Mean-6.55, SD: 0.92) and Accommodating (Mean: 5.17 - SD: 0.80). 


\section{Macrothink}

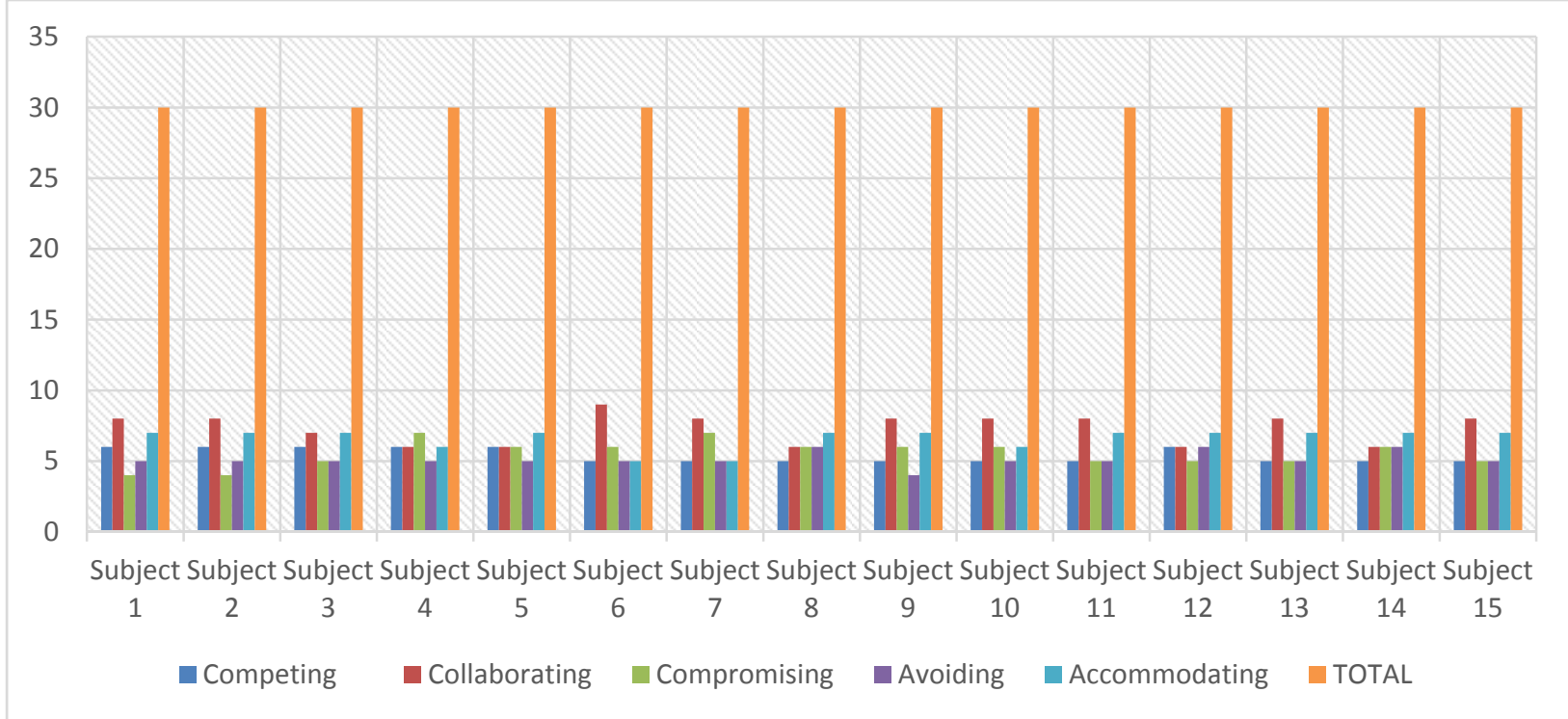

Figure 6. Pre-trg Control Group - Conflict Management Scores

The above graph reveals that the conflict management styles of fifteen subjects who were in the control group includes the major components like: Competing (Mean: 5.09 - SD: 0.48), Collaborating (Mean-6.93 - SD: 1.01), Compromising (Mean-5.24, SD-0.88), Avoiding (Mean-4.84, SD: 0.49) and Accommodating (Mean: 6.23 - SD: 6.23).

With reference to the conflict management styles of subjects in control group (Mentioned in the graph above), the subjects in the experiment group have displayed their preferential conflict management style as Competing (Mean: 7.35) compared to the subjects in control group whose preferential style is collaborating (Mean:6.93).

Further, it has been observed that subjects whose preferential conflict management style is competing or avoiding, such subjects comparatively scored very less in EI tests and the subjects who scored less in competing or avoiding and comparatively more in collaborating or compromising have scored high in the EI tests.

\subsection{The Scores of Emotional Intelligence and the Conflict Management Styles Obtained after Training}

The researcher conducted a two-day training program for the experiment group on various modules like emotional intelligence, conflict management styles, team effectiveness and transactional analysis. Parallel to this, the control group was kept under observation. After the training program, the experiment group and control group were closely observed and the conflicts were recorded through social mapping tool over the period of one month. Simultaneously, the Emotional Intelligence inventory and the Conflict Management inventory were administered on both the groups in order to analyze the improvements in the experiment group. The following graph elucidates the scores and illustrates the changes in the experiment group after the training program in comparison to pre-training scores of experiment group. 


\section{Macrothink}

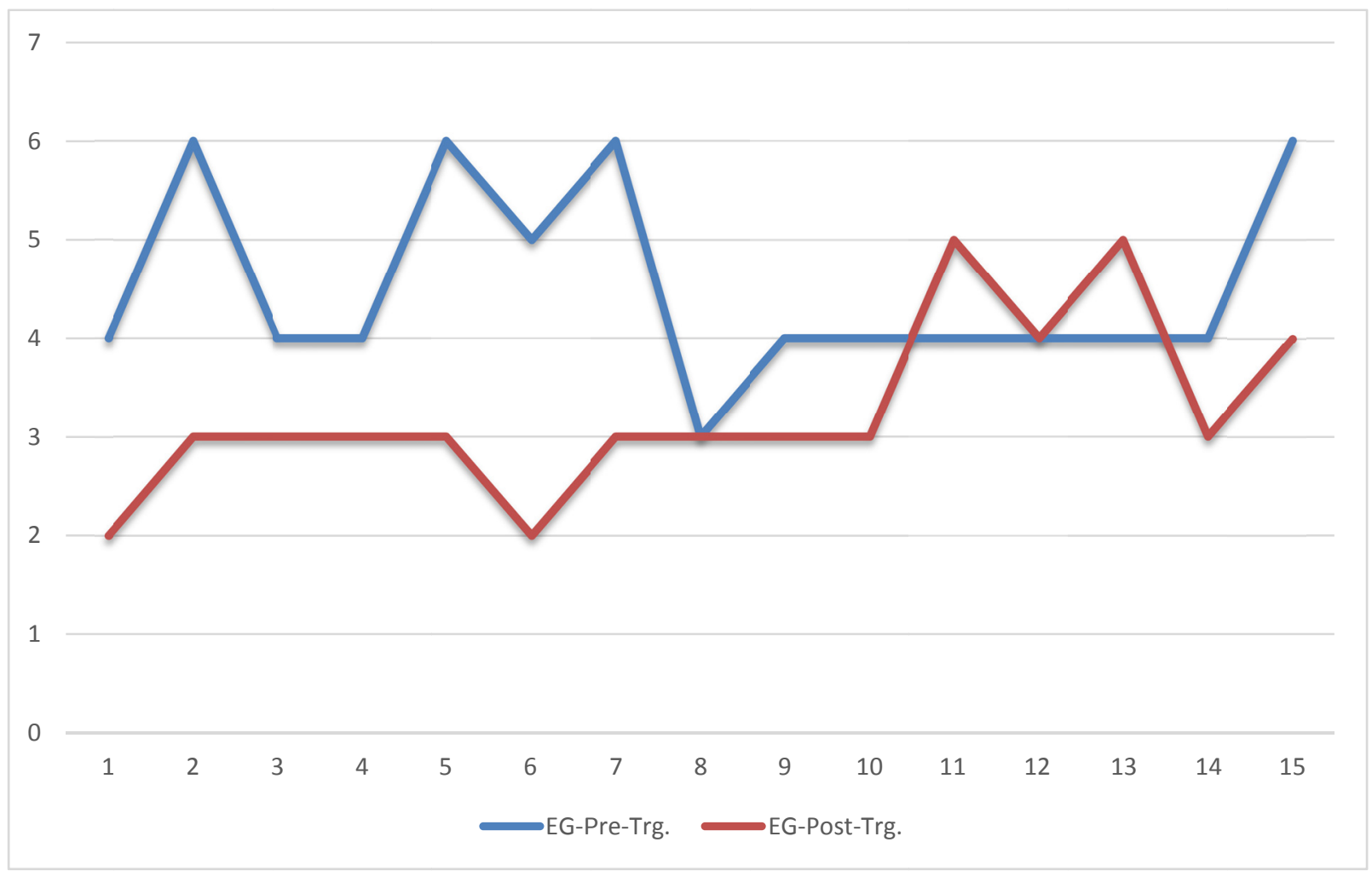

Figure 7. Social mapping analysis of experiment group - pre training \& post training

The graph reflects on the frequency of conflicts of the subjects under experiment group over a period of month prior to the training and post training. It is self-explanatory that experiment group had more frequency of conflicts prior to training (Mean: 4.53) and the conflicts have considerably decreased post training (Mean: 3.26). The correlation between the frequency of conflicts both prior to training and post training is -0.092 .

Further, the researcher had also observed the control group over the period of one month after providing training to the experiment group and recorded the frequency of conflicts among the subjects on day to day basis. The comparative data pertaining to the frequency of conflicts among the control group both prior and post training (for the experiment group) has been given below: 


\section{Macrothink}

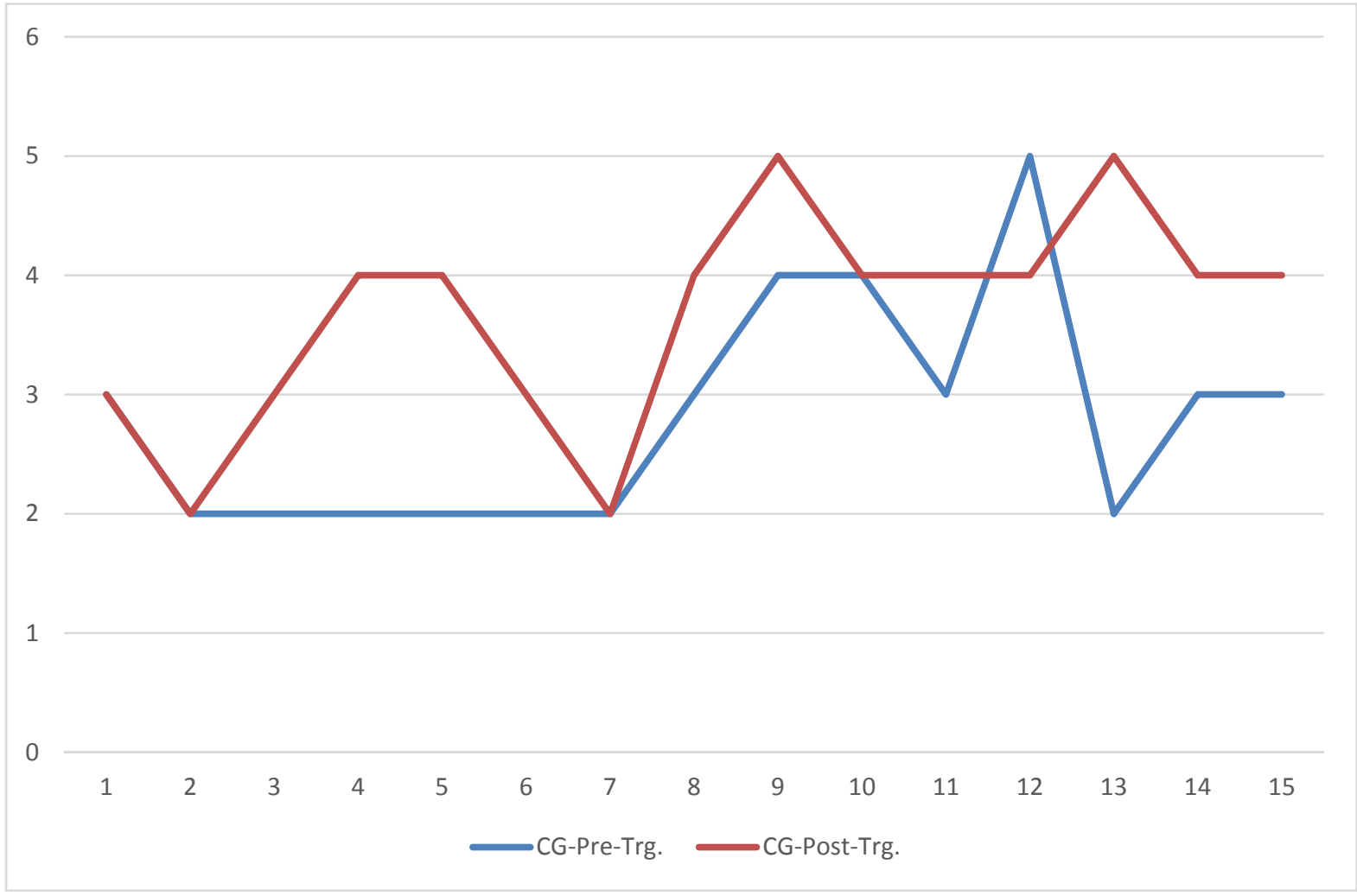

Figure 8. Social mapping analysis of control group - pre training \& post training

As it is reflected in the above graph, the subjects among the control group had a certain frequency of conflicts over a month (Mean: 2.8) wherein the minimum frequency of conflicts were 2 and the maximum were 5. During the post training, the subjects among the control group who have not received any interventions had reported to have more frequency of conflicts (Mean: 3.66) wherein the average frequency of conflicts had been increased comparatively.

In order to ascertain the considerable changes occurred in terms of conflicts among the experiment group, the researcher has compared the frequency of conflicts by the subjects of experiment group in comparison to the subjects of control group. The graph is given below: 


\section{Macrothink}

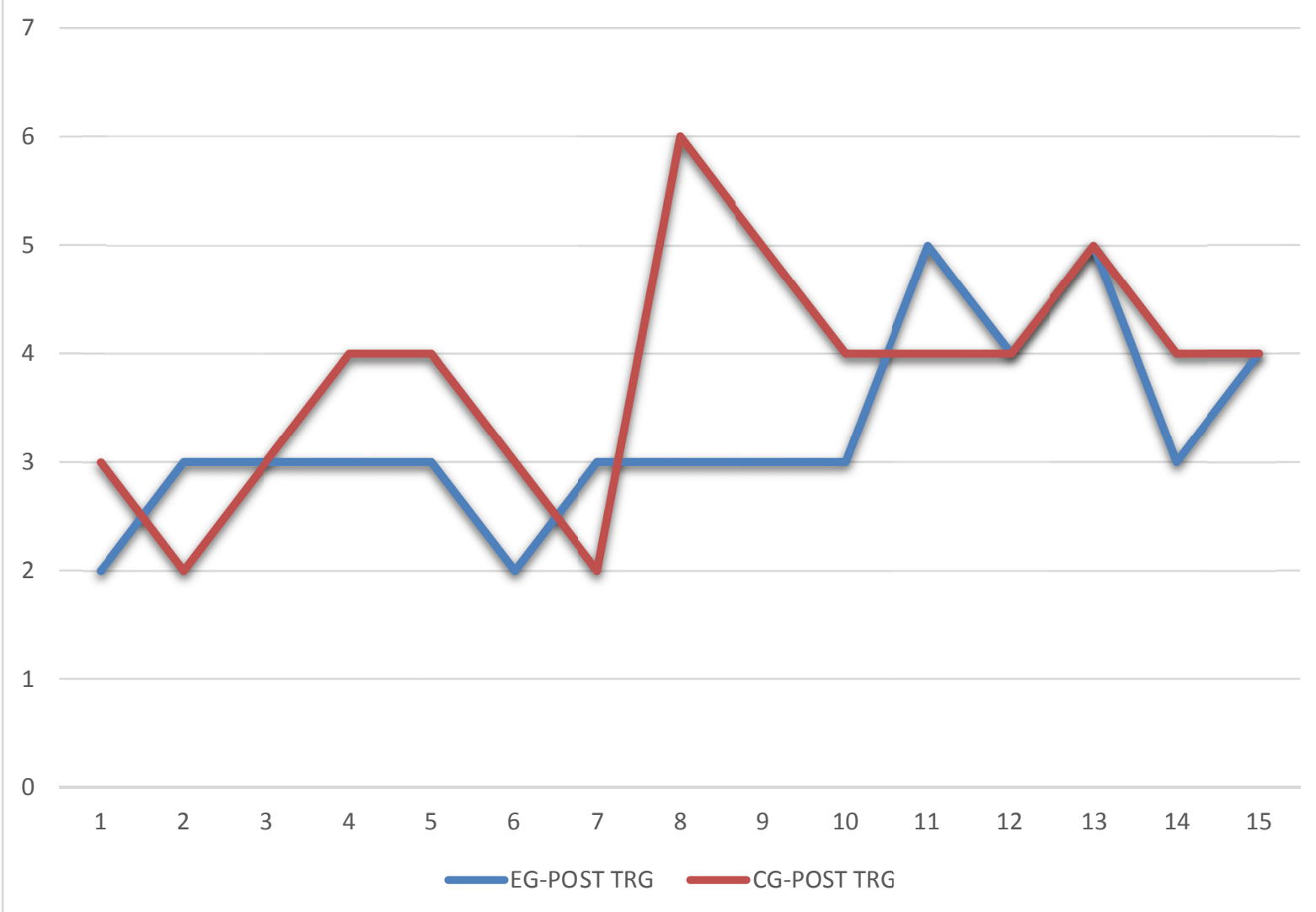

Figure 9. Social mapping of experiment and control group - post training

In comparison to the Control Group (Mean: 3.8), the subjects in the experiment group (Mean: 3.2) have reportedly less frequency of conflicts over a period of one month. The correlation between the Experiment Group and Control Group is 3.26. The statistical report confirms that the subjects in experiment group have reduced conflicts in a month after undergoing the intervention (Training Program)

\subsection{Scores of Emotional Intelligence and Conflict Management of Experiment Group (Post} Training)

As per the research plan, the experimenter administered the EI and CFM tests on the experiment group post-training in order to record the impact of the intervention program. The following graphs reflect on the score obtained by each subject both in emotional intelligence and conflict management styles. 


\section{Macrothink}

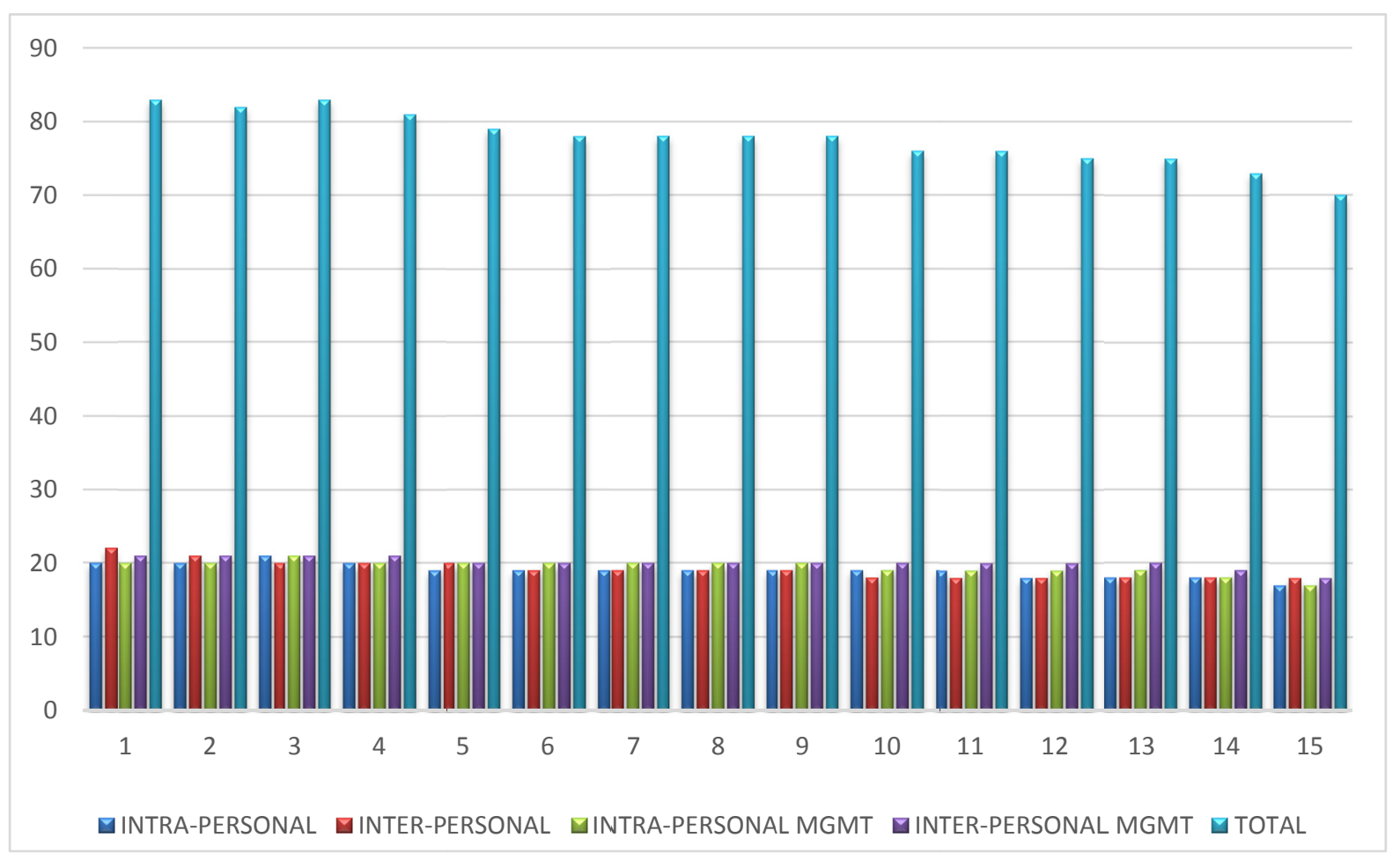

Figure 10. Post-trg - Experiment Group - Emotional Intelligence Scores

The above graph reflects on four components of EI Inventory and the scores of each subject on each component and the maximum score for each component is 25 . As it is reflected, the intrapersonal awareness component has the mean score of 17.87, the mean score of interpersonal awareness is 18.00 , the mean score of intra-personal management is 18.30 and the mean score of interpersonal management is 18.86 . The average total score of subjects (out of 100) is 77.66. As per the interpretation of the EI inventory, the scores reflect that the subjects have good emotional intelligence.

Moreover, the comparative analysis was made by the researcher in order to understand if there any improvement in the scores of EI among the subjects of Experiment group after the intervention program. The same is given below: 


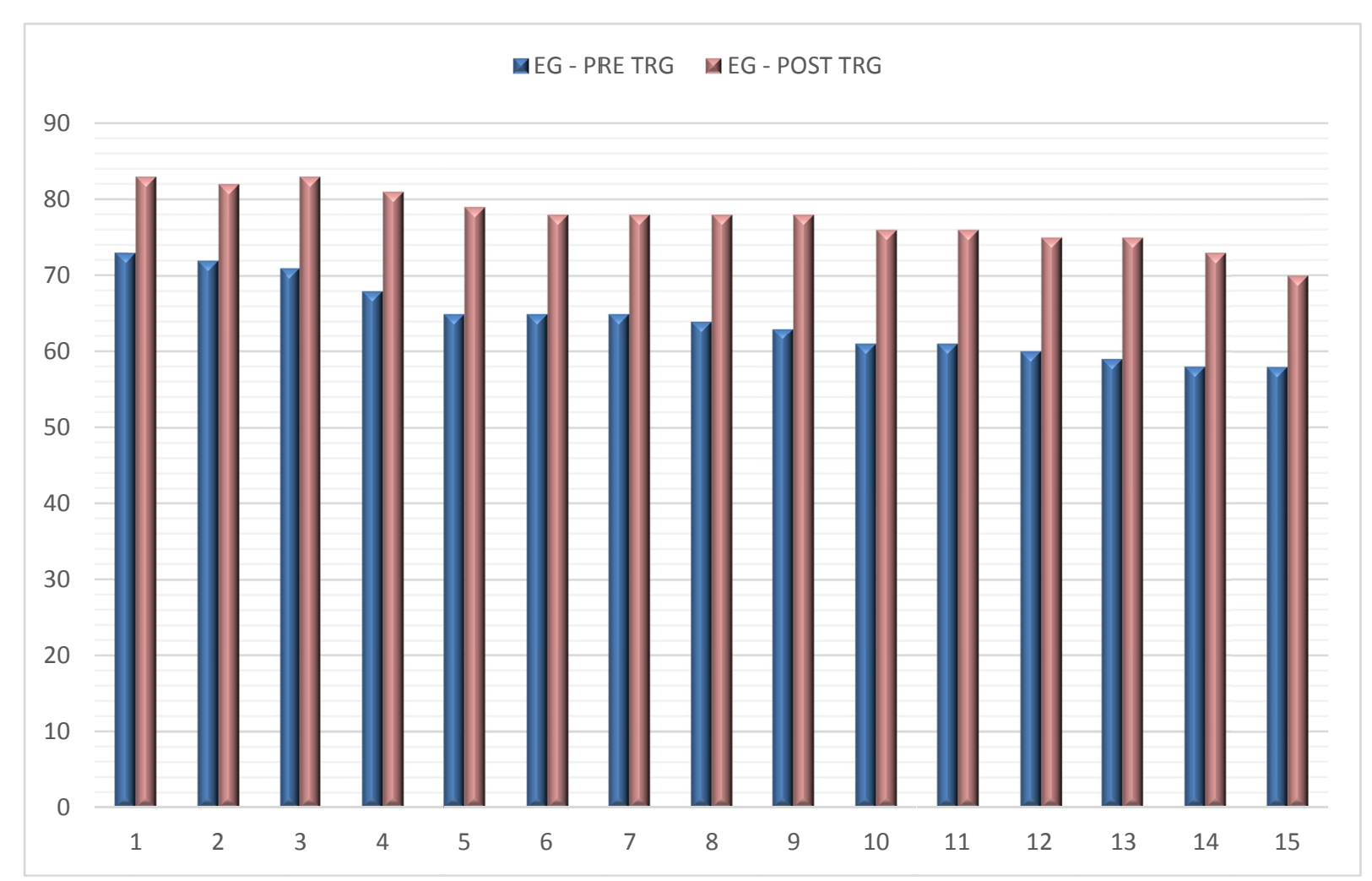

Figure 11. Experiment Group - EI Pre Trg and Post Trg Analysis

It is quite vivid that the experiment group scored the average of 64.2 prior to the intervention program and the score increased to the average of 77.66 after the intervention program. As a result of the intervention program, the experiment group has showed considerable progress in their emotional intelligence level.

Further, the researcher has also compared the EI scores of experiment group and control group after the intervention program for the experiment group. The graph is given below: 


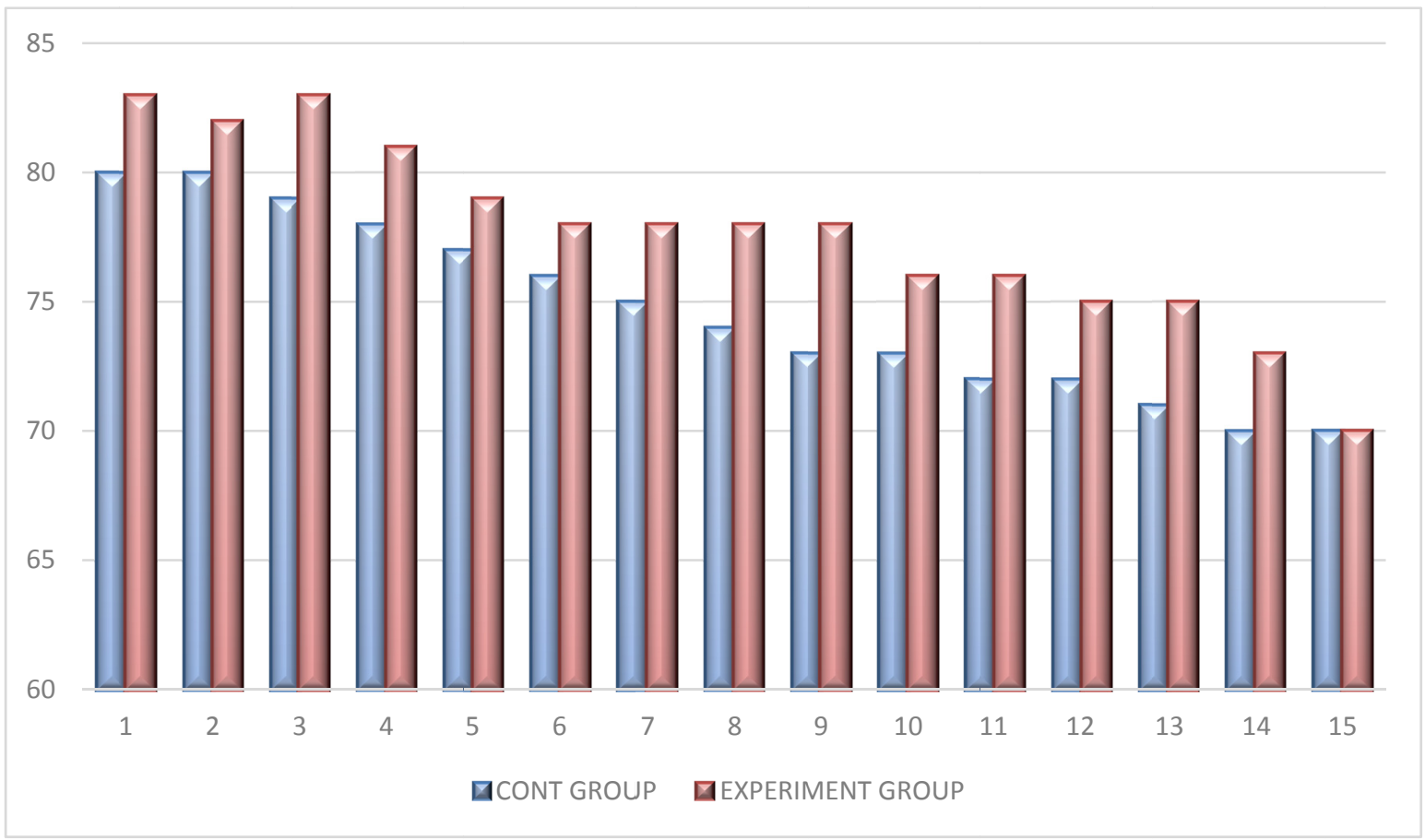

Figure 12. EI scores of exp. and cont. Groups - post training - analysis

The above graph ascertains the fact that experiment group has made some encouraging betterment in the status of the emotional intelligence compared to control group as the experiment group has the mean score of 77.66 and the control group has the mean score of 74.66. Accordingly, the researcher strongly ascertains that intervention program had a promising impact on the experiment group.

\subsection{Scores of Experiment Group and Control Group in Conflict Management Styles}

Simultaneous to the administration of EI test, the researcher also administered the Kilmann's Conflict Management Inventory on both the groups in order the preferential conflict management style of each subject so that the researcher can understand how the conflict management styles are directly inferential to the emotional intelligence of the subject. 


\section{Macrothink}

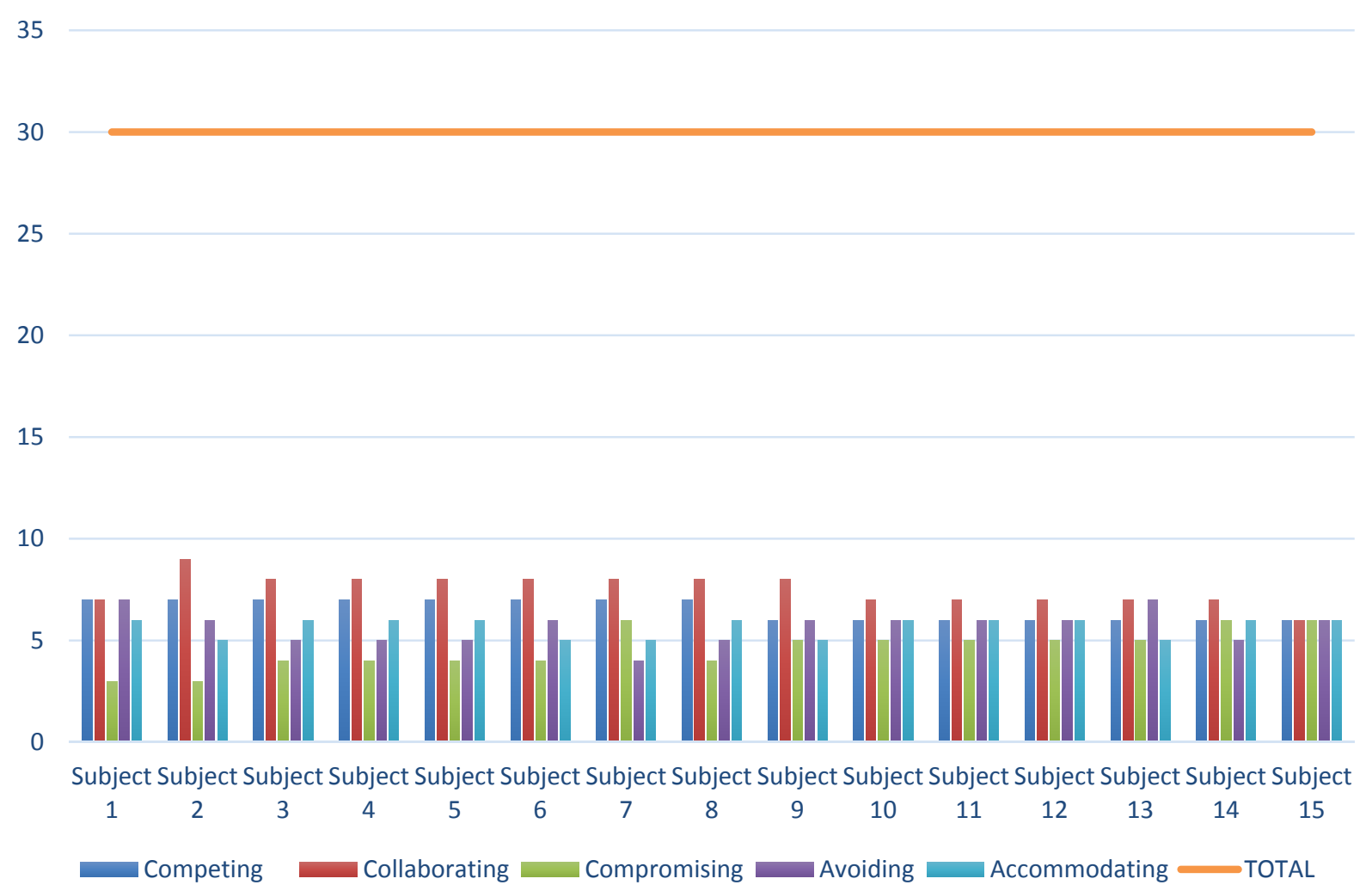

Figure 13. Experiment Group - Conflict Mgmt. Scores - Post Training

The above graph reflects on the preferred conflict management styles of 15 subjects from experiment group and the total score is 30 and the maximum score for each component is 9 . As reflected in the graph, the subjects have the mean score of 6.15 (STDEV: 0.498887652) in Competing, the mean score of 7.10 (STDEV: 071) in Collaborating, the mean score of 4.37 (STDEV: 0.95) in Compromising, and the mean score of 5.34 (STDEV: 0.47) in Accommodating.

The graph given below reflects the analysis of conflict management scores obtained by the experiment group both pre-training and post-training. 


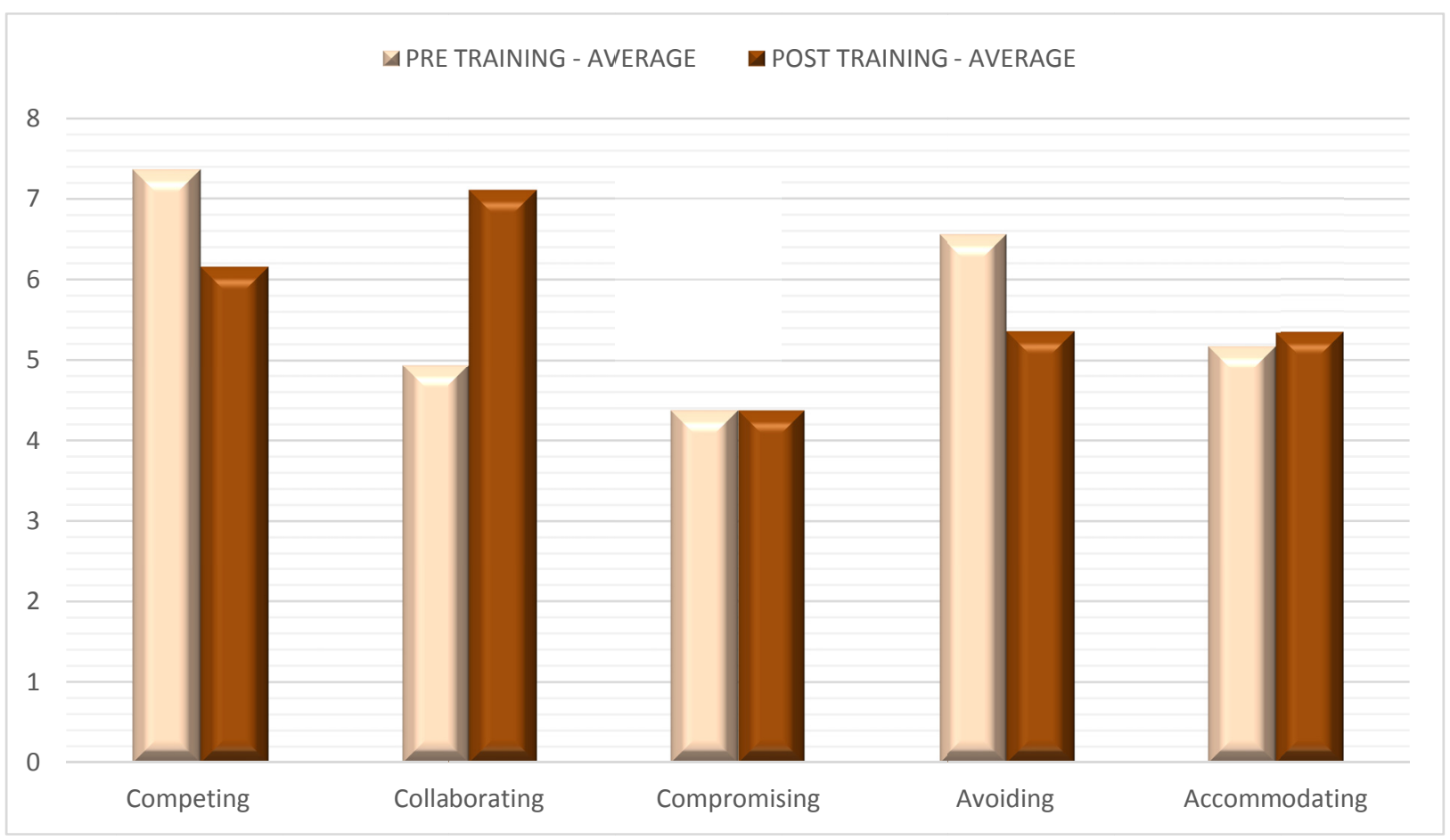

Figure 14. Conflict Management Scores of Exp. Group Pre-Trg and Post-Trg - Analysis

It is quite vivid through the graph that the experiment has group has made perceptible improvements in their preferred conflict management styles after the intervention program. Moreover, it is also stated in the study that the people with competing and avoiding as their preferred style will have very less EI scores and the people with collaborating or avoiding will have high EI scores.

As reflected in the graph above, the average score of experiment group in Competing both pre and post training are 7.35 and 6.15, respectively. The average score in Collaborating both pre and post training are 4.93 and 7.10 , respectively. The average score in Compromising both pre and post training are 4.37 and 4.37, respectively. The average score in Avoiding both pre and post training are 6.55 and 5.36, respectively. In the last component 'Accommodating', the average score both pre and post training are 5.17 and 5.34, respectively.

With reference to the data analysis as furnished above, it can be understood that the experiment group has considerable increase of scores in the components of Collaborating and Accommodating after the intervention program compared to their preferred style of Competing and Avoiding prior to the intervention program.

The following graph reflects on the conflict management styles preferred by both experiment group and control group after the intervention program initiated for the experiment group while the control group was under observation. 


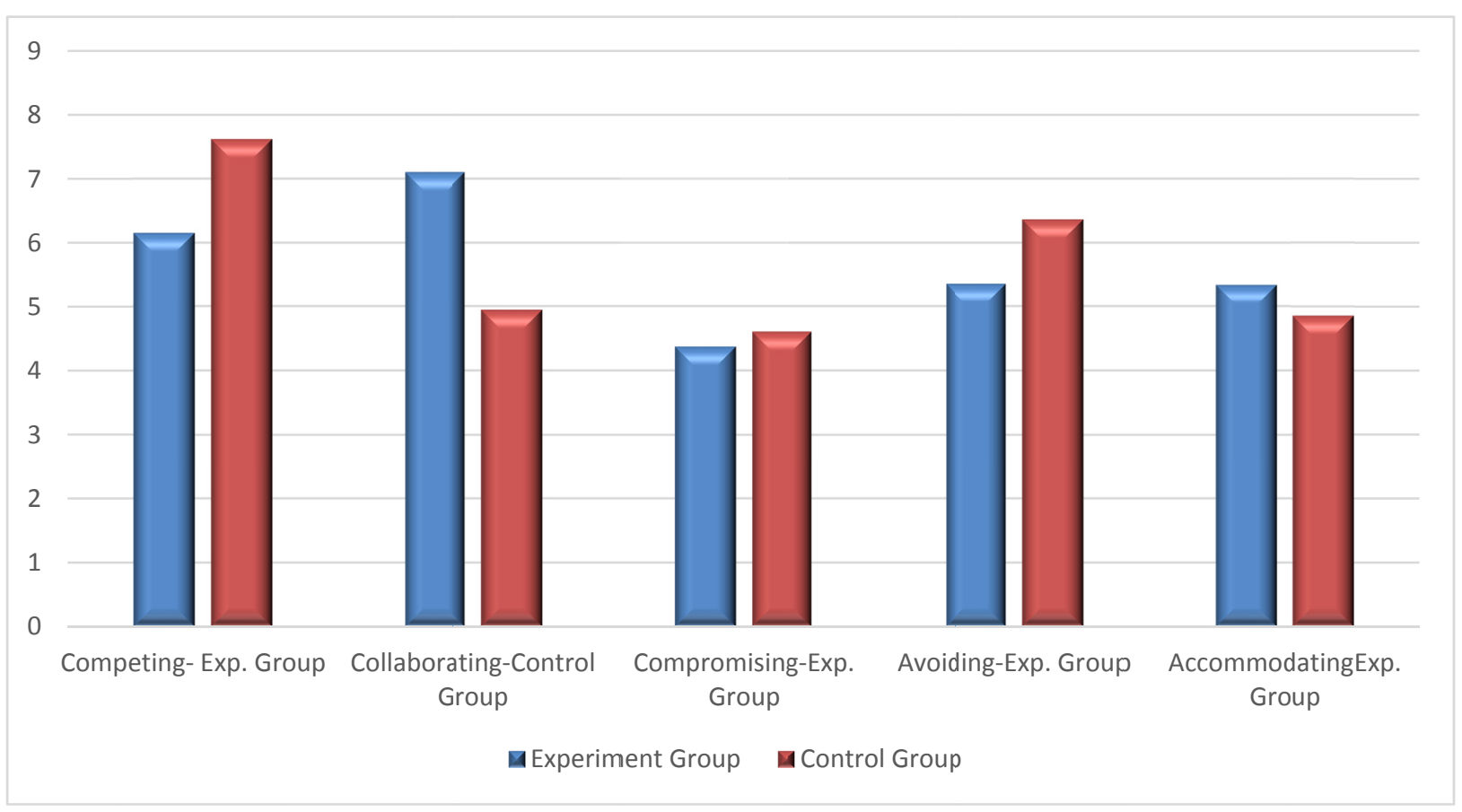

Figure 15. Conflict Management Scores - EXP \& CONT Groups - Post Training - Analysis

The above chart shows that the experiment group has the average of 6.15 in Competing and the control group has the average of 7.62. Further, the experiment group has the average of 7.10 and the control group has the average of 7.10 in Collaborating. The experiment group has the average of 4.37 and the control group has 4.60 in Compromising. In addition, the experiment group has the average of 5.36 and the control group with the average of 6.36 in Avoiding. Besides, the experiment group has the average of 5.34 and the control group with 4.85 in Accommodating.

Based on the analysis of conflict management styles of both experiment and control group, it can be inferred that the experiment group has preferred collaborating and the least preferred is competing compared to control group. Therefore, it can be ascertained that the experiment group has increased level of emotional intelligence compared to control group after the intervention program.

\section{Conclusion of Findings:}

To summarize the results, the researcher highlighted a list of important conclusions based from the statistical analysis throughout the research:

- The subjects were total 30 in number and all the subjects were post-graduates working as the trainers in the organization.

- The subjects in experiment group and control group have recorded high frequency of conflicts during the social mapping. 
- The subjects were administered the Emotional intelligence test wherein the subjects scored comparatively less in the four components like; Intra-personal Awareness, Inter-personal Awareness, Intra-personal Management and Inter-personal Management.

- Simultaneously, the researcher administered Thomas-Kilmann's Conflict Management Inventory having the components like; Competing, Collaborating, Avoiding, Compromising and Accommodating.

- As presumed, the subjects scored very high in competing and avoiding. In this regard, it is inferred that the subjects with high scores in competing and avoiding have less Emotional Intelligence.

- The researcher adopted social mapping tool and recorded the frequency of conflicts among the subjects (30 in number) over the period of one month. The subjects recorded high frequency of conflicts among the subjects.

- Later, the 30 subjects were divided into Experiment group and Control group. The subjects, comparatively, with high frequency of conflicts were included under Experiment group and the remaining were absorbed under control group.

- The variables like gender, age, and culture are not considered in the study.

- The Independent variable- Emotional Intelligence and the dependent variable conflict management styles were considered in the study.

- Later to the observation period, the experiment group were put through a two day intervention program.

- Further, the experiment group and the control group were kept under observation through social mapping. Accordingly, the researcher recorded the conflicts of each subject on day to day basis.

- After social mapping and recording of conflicts, the researcher administered tests on emotional intelligence and conflict management during post-intervention program.

- The subjects in experiment group showed improvement in their conflict management styles. They scored more in collaborating and compromising which is an indication of improvement. However, the control group did not show any sign of improvement in their conflicting behaviour.

- Moreover, the subjects of experiment group comparatively neutralized their conflicting behaviour as they reported very less frequency of conflicts during post-intervention program.

- Evidently, the experiment group achieved high scores in the emotional intelligence and low scores in the conflict management style 'Competing'.

- Indeed, it has been proven that the intervention program was successful in achieving its presumption that the training program on conflict management and transactional analysis may improve the emotional intelligence among the members. Consequently, this result in low frequency of conflicts among the professional in the workplace.

\section{References}

Barbuto, J, \& Ye, X. (2006). Sources of motivation, interpersonal conflict management styles \& leadership effectiveness: A structural model. Psychological Reports, 98(1), 3-20.

Bass, B. M. (1998). Transformational Leadership, Industry, Military, and Educational Impact, 
New Jersey: Lawrence Erlbaum Associates, Inc.

Berne, Eric. Games People Play-the Basic Hand Book of Transactional Analysis. Ballantine Books. New York: 1964

Berne, Eric. Transactional Analysis in Psychotherapy: A Systematic Individual and Social Psychiatry. Grove Press. New York: 1971

Berne, Eric. Transactional Analysis in Psychotherapy: A Systematic Individual and Social Psychiatry. Grove Press. New York: 1971

Berne, Eric. What Do You Say After You Say Hello. Bantam Books. New York: 1973

Blake, R. R., \& Mouton, J. S. (1964). The managerial grid, in M. A. Rahim, (1986). Managing Conflict in Organizations, New York: Praeger.

Brewer, N., Mitchell, P., \& Weber, N. (2002). Gender roles, organizational status, and conflict management styles. The International Journal of Conflict Management, 13(1), 73-94.

Byron, K. (2008). Differential effects of male and female managers' non-verbal emotional skills on employees' ratings. Journal of Managerial Psychology, 23(2), 118-134. doi: $10.1108 / 02683940810850772$

Dattner, B. (2003). Succeeding with emotional intelligence [PDF document]. Retrieved from http://www.dattnerconsulting.com/presentations/ei.pdf

DiMatteo, M. R., Friedman, H. S. \& Taranta, A. (1979). Sensitivity to bodily non-verbal communication as a factor in practitioner-patient rapport. Journal of Nonverbal Behavior, 4, $18-26$.

Dusay, John. Egograms- How I See You and You See Me. Harper \& Row. London: 1977

Elsayed-Ekhouly, S. M., \& Buda, R. (1996). Organizational conflict: a comparative analysis of conflict styles across cultures. The International Journal of Conflict Management, 7(1), 71-81.

Follet, M. P. (1940). Constructive conflict, in M. A Rahim, (1986). Managing Conflict in Organizations, New York: Praeger.

Friedman, R. A, Tidd, S. T., Currall, S. c., \& Tsai, 1. C. (2000). What goes around comes around: the impact of personal conflict style on work conflict and stress. The International Journal of Conflict Management, 11, 32-55.

Funder, D. C. \& Harris, M. 1. (1986). On the several facets of personality assessment: the case of social acuity. Journal of Personality. 54,528-550.

Getzels, 1. W., \& Guba, E. G. (1954). Role, role conflict and effectiveness: An empirical study, in M. A Rahim, (1986). Managing Conflict in Organizations, New York: Praeger.

Goleman, D. (1996). Emotional intelligence: Why it can matter more than IQ, London: Bloomsbury. 
Goleman, D. (1998) Working with Emotional Intelligence, New York: Bantum Books.

Goleman, D. (2004, January). What makes a leader? Harvard Business Review, 82(1), 82-91.

Graham, P. (1998). Saying "no" to compromise; "yes" to integration. Journal of Business Ethics, 17, 1007-1-13.

Hay, Julie. Transactional Analysis for Trainers. Sherwood Publishing. UK: 2009

Herbst, T. H., \& Maree, K. G. (2008). Thinking style preference, emotional intelligence and leadership effectiveness. SA Journal of Industrial Psychology, 34(1),32-41.

Hoffman, L. R., \& Maier, N. R. F. (1961). Quality and acceptance of problem solution by members of homogenous and heteregeous goups. Journal of Abnormal and Social Psychology, $62,401-407$.

Hogan, R., Curphy, G. \& Hogan, 1. (1994). What we know about leadership effectiveness and personality, in B. Palmer, M. Walls, Z. Burgess, \& C. Stough (2000). Emotional intelligence and effective leadership. Leadership \& Organization Development Journal, 22(1), 5-10.

House, R. 1. \& Aditya, R. N. (1996). The social scientific study of leadership: quo vadis. Journal of Management, 13(5), 409-443.

Howard Gardner, Frames of Mind: The Theory of Multiple Intelligences, New York, 1983

Ian Stewart \& Vann Joines. TA Today. Lifespace Publishing. England: 1987

Ivancevich, J. M., \& Donnelly, 1. H., Jr. (1974). A study of role clarity and need for clarity for three occupational groups, in M. A. Rahim, (1986). Managing Conflict in Organizations, New York: Praeger.

Jameson, 1. (1999). Toward a comprehensive model for the assessment and management of intra organizational conflict: developing the framework. The International Journal o/Conflict Management, 10, 268-294.

Janssen \& van de Vliert, E. (1996). Concern for other's goals: key to (de-) escalation of conflict. The International o/Conflict Management, 7, 99-120.

John D. Mayer and Peter Salovey, Emotional Intelligence, Baywood Publishing Company, New York, 1990.

Jonathan H. Turner \& Jan E. Stets, Handbook of the Sociology of Emotions, Cambridge University Press, London, 2006

Ju1ian, 1. W., \& Perry, F. A. (1967). Cooperation contrasted with intra-group and inter-group competition. Sociometry, 30, 79-90.

Kerr, R., Garvin, 1. Heaton, N., \& Boyle, E. (2006). Emotional intelligence and leadership effectiveness. Leadership \& Organization Development Journal, 27(4), 265-279. 


\section{Macrothink}

Korbanik, K., Baril, G. L., \& Watson, C. (1993). Managers' conflict management style and leadership performance: The moderating effects of gender. Sex Roles, 29, 405-420.

Langley, A. (2000). Emotional Intelligence-a new evaluation for management development. Career Development International, 5(3), 177-183.

Likert, R. (1967). The human organization: Its management and value. New York: McGraw-Hill.

Likert, R., \& Likert, 1. G. (1976). New ways 0/ managing conflict. New York: McGraw-Hill.

Munduate, L., Ganaza, 1, Peiro, J., \& Euwema, M. (1999). Patterns of styles in conflict management and effectiveness. The International Journal of Conflict Management, IO, 5-24.

Palmer, B., Walls, M., Burgess, Z., \& Stough, C. (2000). Emotional intelligence and effective leadership. Leadership \& Organization Development Journal, 22(1), 5-10.

Riggio, R. E., \& Reichard, R. J. (2008). The emotional and social intelligences of effective leadership: an emotional and social skill approach. Journal ofManagerial Psychology, 23(2), 169-185.

Sorenson, R., Morse, R., \& Savage, G. (1999). A test of the motivations underlying choice of conflict strategies in the dual-concern model. The International Journal of Conflict Management, 10,25-44

Srinivasan, P. T. \& George, S. (2005). A study on the relationship of emotional intelligence and conflict management styles among management students. The Vision Journal of Management and Allied Sciences, 11 (4), 1-6.

Steiner, Claude. Scripts People Live. Grove Press. New York: 1994

Thomas and Harris, Amy. I'm OK You're OK. Harper \& Row Publication. USA: 1967

Thomas and Harris, Amy. Staying OK. Harper Collins Publication. USA: 1987

Thomas K. W. (1976), Conflict and conflict management, Handbook of industrial and organizational psychology. Rand McNally. Chicago: 1990

Thomas, K. W., \& Kilmann, R. H. (1974). The Thomas-Kilmann mode instrument. NY: Xicom.

Wagner, Abe. The Transactional Manager. Spiro Press. UK: 1980

Woollams \& Brown. The Total Handbook of Transactional Analysis. Prentice Hall. London: 1979

\section{Copyright Disclaimer}

Copyright reserved by the author(s).

This article is an open-access article distributed under the terms and conditions of the Creative Commons Attribution license (http://creativecommons.org/licenses/by/3.0/). 